\title{
CONSCIÊNCIA LITERÁRIA E POSICIONAMENTO POLÍTICO NO PROCESSO DE COMPOSIÇÃO DE THE VOYAGE OUT, DE VIRGINIA WOOLF
}

Maria Alessandra Galbiati é doutoranda em Teoria da Literatura do Programa de Pós-Graduação em Letras na UNESP de São José
do Rio Preto-SP e bolsista da CAPES. E-mail: maria.alessandra@hotmail.com

Resumo: Neste artigo, propomos uma discussão sobre as implicações e desdobramentos da relação entre Literatura e Política, com o intuito de desmistificar certas posições críticas generalizadas no âmbito dos estudos literários. Para isso, fazemos algumas articulações entre teoria e aspectos do processo de composição do primeiro romance de Virginia Woolf, destacando a habilidade literária e a consciência política da autora.

\begin{abstract}
In this article, a discussion about the implications and developments in the relation between Literature and Politics is proposed in order to demystify generalized critical opinions in literary studies. To do this, articulations between theory and practice are made, based on Virginia Woolf's composition process of her first novel, pointing out the author's artistic ability and political consciousness.
\end{abstract}

\section{Introdução}

Quando pensamos na aproximação entre literatura e política, geralmente, somos levados a uma abordagem marxista ou sociológica da literatura. O problema maior nesse tipo de associação é que a idéia geral sobre a relação literatura-política e suas implicações é, por muitas vezes, reducionista, equivocada ou mal-interpretada, caindo em generalizações de senso comum.

No atual contexto dos estudos literários, ao se estudar as inter-relações entre literatura e política, faz-se necessário revisar as posições consideradas "marxistas" ou “sociológicas” sobre questões estéticas, criação literária, liberdade do artista e expandir a noção de teoria/crítica marxista da literatura. Além disso, é sempre importante termos em mente que o paradigma marxista ou sociológico é “uma” das várias visões possíveis de abordagem da literatura.

Mais do que isso, sabermos que "o marxismo" é uma ficção. Do pensamento marxiano à tradição marxista, o que se vê "é uma série de interpretações e acréscimos variados da obra de Marx, condicionados, cada um deles, por injunções históricas, culturais, políticas, etc.” (Netto, 1994, p. 75), em momentos e lugares de enunciação específicos.

Ao longo do trabalho, observaremos que falar sobre literatura e política implicará também abordar a produção literária em conjunto com a sociedade. Em outras palavras, significa retomar a antiga tentativa de se definir literatura. Nesta direção, o literário, o político e o social estão imbricados e em constante interação com os contextos de produção/recepção.

Para a problematização do complexo entre literatura, política e contexto sóciocultural, vinculado à noção de concepção de mundo, utilizaremos as reflexões de 
Wellek e Warren (1955), Candido (1980), Eagleton (1978, 1983) e Sartre (1999), principalmente. Por fim, como exemplo de uma escrita literária que consegue articular questões sociais, políticas e históricas, destacamos o processo de composição de The Voyage Out, o primeiro romance de Virginia Woolf, publicado em 1915.

\section{Literatura e Política: em busca de uma crítica literária marxista?}

Ao falarmos sobre marxismo, deparamo-nos com o retorno (quase) inevitável ao pensamento de Marx e de Engels. Embora cada um tenha tido sua visão particular da história, "both looked for the social grounding of a literary work and valued its fidelity to history without, however, insisting on a normative form of representation" (Cohen, 1992, p. 321). Independentemente, sabemos que a obra de Marx fundou um modo original de pensar a sociedade burguesa e a sua dinâmica.

A tentativa de elaboração de uma teoria social por Marx e Engels, com o passar dos anos, acabou sendo (re)interpretada e (res)significada de diversas maneiras. A obra marxiana serviu de fundamentação para o desenvolvimento de inúmeras correntes que, "no seio de um bloco teórico-cultural diferenciado, oferecem tratamentos complementares, alternativos e/ou excludentes para os problemas que se foram e vão colocando no mundo burguês e nas suas ultrapassagens revolucionárias” (Netto, 1994, p. 76-77).

No interior da tradição marxista, propostas diversificadas entrecruzaram-se e diferentes posições confrontaram-se, seja devido ao apelo intelectual seja a sua funcionalidade política. A história da constituição de uma teoria literária materialista (proposta inicial), renomeada teoria literária marxista, é repleta de descontinuidades e contradições. Por isso, devemos evitar uma abordagem esquemática ou leitura simplista de tal percurso crítico-teórico, principalmente, fora do contexto mais amplo da história do movimento operário internacional.

Em termos morfológicos, a palavra "marxismo" (Marx + -ismo) traz embutido certa arbitrariedade na escolha de critérios e referenciais de análises e propostas. Expandindo tal perspectiva, Netto (1994, p. 77-78) explica-nos que

O que a denominação marxismo traz consigo, como um contrabando ideológico, é o abandono da historicidade da contribuição de Marx e dos que o sucederam: induzindo à idéia de uma linha contínua entre o pensamento marxiano e os projetos nele inspirados, obscurece os condicionamentos históricos, teóricos, culturais e políticos que respondem pelas várias interpretações, subtrações e adições realizadas em torno da obra de Marx.

Por outro lado, ao estudar a aplicação da teoria marxista à abordagem de questões artísticas, entendendo o marxismo como uma teoria científica das sociedades humanas, Terry Eagleton propôs-se a mostrar que tal aplicação não representa um sistema estético estanque e acabado, mas sim, que “essa crítica se modifica à medida 
que se modifica a história em que está enraizada” (1978, p. 10). Prova disto são as contribuições importantes de Plekhanov, Caudwell, Lukács e Goldmann à teoria da literatura. Nestes estudos, de modo geral, observamos um vínculo entre arte, economia e classes sociais. A imagem preconceituosa de uma crítica marxista que seria contra a "liberdade" do artista, reduzindo-o a um simples "escravo do processo econômico", poderia ter nascido de uma interpretação do realismo socialista como produto da ditadura stalinista.

Cabe aqui destacar que a aproximação entre uma estética realista, uma atividade crítica e uma forma de governo pode ter resultado em uma visão cristalizada e reducionista na relação entre produção artística (e literária) e um sistema político. Nas palavras de Hattnher,

A indissociação entre "crítica marxista” e "posturas relativas à produção e críticas literárias nos anos que sucederam a ascensão de Stalin ao poder na URSS” é extremamente reducionista, uma vez que não inclui em seu raciocínio os desenvolvimentos posteriores da utilização do marxismo na crítica literária, em especial (e, obviamente) fora da União Soviética (Hattnher, 1998, p. 10, grifo do autor).

Segundo Wellek e Warren (1955), a crítica marxista atinge sua melhor fase quando tenta expor as implicações sociais latentes na obra de um escritor, visto que a literatura nasce num contexto social, como parte de uma cultura, num meio ambiente. Nesse complexo, abre-se caminho para os estudos sociológicos da literatura e, assim, as abordagens marxistas ampliam seus objetos e objetivos para questões extratextuais, diversificando métodos e metodologias.

O termo "político" refere-se ao modo como nossa vida social é organizada em conjunto e às relações de poder que isso implica. A teoria literária está indissoluvelmente ligada às crenças políticas e aos valores ideológicos de um determinado período histórico-cultural, isto é, a teoria literária pode ser compreendida como "uma perspectiva na qual vemos a história de nossa época” (Eagleton, 1983, p. 210).

A idéia de que a teoria literária seja "pura” é um mito acadêmico. A cada postura teórica vê-se a adoção de uma posição ideológica e, essas teorias variadas acabam reforçando os interesses particulares de grupos específicos de pessoas, em momentos determinados. Por isso, chega-se à conclusão de que tanto a teoria quanto a crítica são políticas. Sob tal ponto de vista, Eagleton (1978, p. 11) relaciona a crítica marxista no campo mais amplo de análise teórica das ideologias, isto é,

[...] as ideias, valores e sentimentos através dos quais os homens tomam consciência, em diversas épocas, da sociedade em que vivem. E algumas dessas ideias, valores e sentimentos só nos são acessíveis na literatura. Compreender as ideologias é compreender tanto o passado como o presente com mais profundidade; e essa compreensão contribui para a nossa libertação. 
Desta maneira, os críticos deveriam assumir uma postura maleável, almejando, na medida do possível, a abrangência do social, sem ser superficial, e a especificidade das opções formais, conforme observamos na seguinte citação:

Essa crítica deve também levar em consideração que aquilo que se diz puramente formal é também elemento componente do plurivalente adjetivo "social”. O social, por sua vez, filtra-se através do estético, do formal, brotando na obra literária. Assim, externo e interno, social e formal representam a dualidade dialética cuja resultante final é a literariedade (Hattnher, 1998, p. 14, grifo do autor).

Para complementar, podemos entender uma obra literária na sua integridade "fundindo texto e contexto numa interpretação dialeticamente íntegra” (Candido, 1980, p. 4), em que tanto o ponto de vista que explicava a obra pelos fatores externos quanto à noção de que a estrutura é virtualmente independente, sejam compreendidos como dois momentos necessários do processo de interpretação. E, neste movimento dialético, a corrente crítico-teórica e a orientação do que se entenda por literatura são elementos fundamentais.

\section{Literatura: definições e implicações}

Qualquer tentativa de definição da literatura tende a confundir-se com a definição do poético e da beleza. Tal questão ainda permanece não resolvida, uma vez que parece ser "impossível de desvinculá-la da questão do gosto, da regência de usos e costumes e situações contextuais, da ideologia, de relativizações de toda ordem” (Wanderley, 1992, p. 253). A cada tentativa, discute-se acerca da natureza e da função da literatura, que variam significativamente, de acordo com os interesses particulares de um grupo em uma determinada época histórica.

Quais são os critérios para se classificar um texto como literário ou não? Dentro dos tratados de teoria literária, uma das possíveis respostas baseia-se no modo especial de utilização da linguagem:

A maneira mais simples de resolver o problema é a de pôr em evidência o modo particular de utilização da linguagem na literatura. A linguagem é o material da literatura, tal como a pedra ou o bronze o são da escultura, as tintas da pintura, os sons da música. Mas importa ter presente que a linguagem não é uma matéria meramente inerte como a pedra, mas já em si própria uma criação do homem e, como tal, pejada da herança cultural de um grupo lingüístico (Wellek e Warren, 1955, p. 28).

A literatura acaba sendo caracterizada por um uso peculiar da linguagem: um tipo de linguagem que chama a atenção sobre si mesma e exibe sua existência material, diferentemente da fala cotidiana. 
Outra resposta possível é que "a definição de literatura fica dependendo da maneira pela qual alguém resolve ler, e não da natureza daquilo que é lido” (Eagleton, 1983, p. 9). Alguns textos são literários por natureza, outros atingem essa condição e a outros essa condição é imposta. Deste modo, a noção do que seja literatura varia, segundo a maneira pela qual as pessoas se relacionam com a escrita e, o sentido do que seja "literário" torna-se historicamente específico.

Se pensarmos literatura como escrita altamente valorizada, deparamo-nos com a noção de que literatura seja algo não eterno e imutável. Os julgamentos de valor acabam influenciando fortemente a classificação do que é considerado literário ou não, sendo eles próprios também passíveis de mudança ao longo da história. Dessa maneira, Eagleton diz-nos que a literatura,

[...] deveria ser entendida como constructo, modelado por determinadas pessoas, por motivos particulares, e num determinado momento. Não existe uma obra ou uma tradição literária que seja valiosa em si, a despeito do que se tenha dito, ou se venha a dizer, sobre isso. "Valor" é um termo transitivo: significa tudo aquilo que é considerado como valioso por certas pessoas em situações específicas, de acordo com critérios específicos e à luz de determinados objetivos (Eagleton, 1983, p. 12, grifo do autor).

Com essa definição, podemos elaborar o seguinte raciocínio: o que é considerado literário ou não varia na medida em que valores e interesses particulares de grupos institucionais pertencentes a uma determinada época histórica alteram-se. Mais do que isso, na nossa estrutura de valores, está oculta a maneira pela qual aquilo que dizemos e no qual acreditamos relaciona-se com as relações de poder da sociedade na qual estamos inseridos. Em outras palavras, os juízos de valor que constituem a literatura são historicamente variáveis e têm uma estreita relação com as ideologias sociais. Referem-se não apenas ao gosto particular, mas também aos pressupostos pelos quais certos grupos sociais exercem e mantêm o poder sobre outros.

Neste artigo, tomamos como ponto inicial a afirmação conhecida de que a literatura é uma instituição social que utiliza a linguagem como meio de expressão específico, e esta, por sua vez, é uma criação social. Assim, a linguagem (literária) é aquela que consegue "representar a vida”, no entanto, sabemos que a literatura não deve ser vista como um mero reflexo de situações vivenciadas dentro de uma sociedade. De qualquer forma, a literatura tem um "papel social” (utilidade), que não pode ser puramente individual. Dessa forma, muitas questões levantadas pelo estudo da literatura são, em última análise, explicita ou implicitamente, questões sociais.

Nesta direção, não há como negar que a literatura seja um modo de expressão artístico no qual expõe as relações entre as pessoas dentro de uma sociedade (hierárquicas, econômicas, políticas, etc.). Também não podemos negar o fato de o escritor ser um membro dessa sociedade, que possui certa condição social e se dirige a um público (fictício ou não) e pelo modo como escreve, observamos suas posições e convicções político-sociais, sua experiência e sua concepção do mundo. 
A literatura somente nasce num contexto social, como parte de uma cultura, num meio ambiente. Mas, para que haja literatura, a nosso ver, é necessário compreender o complexo no qual o texto literário está inserido. Além disso, é igualmente relevante entendermos as condições de produção e de recepção desses textos. Por isso, podemos pensar literatura como um complexo que envolve um escritor, o texto e um leitor e juntamente com esses três elementos, estão embutidos os julgamentos de valor e as ideologias sociais. Neste ponto, vale destacar um autor e seu pensamento crítico-social.

Jean-Paul Sartre captou as grandes idéias-força de um período histórico conturbado e, ao mesmo tempo, promissor, pensando o marxismo como "o espírito do nosso tempo". Sua escrita, ao permitir possibilidades de interpretação, acabou abrindo caminho para a construção de uma postura crítica cristalizada quanto à noção de engajamento e de seus correspondentes desdobramentos (autor engajado e literatura engajada). A indissociação entre produção literária e crítica marxista reduziu parte de sua obra à visão de que o papel da literatura estivesse a serviço de um sistema político/partidário.

No ensaio Que é a Literatura?, Sartre tenta mostrar que a natureza e o papel social da literatura encontram-se organizados em três perguntas básicas sobre a arte de escrever: O que é escrever?, Por que escrever? e Para quem se escreve?

Escrever é uma ação de desnudamento. O escritor revela-se ao escrever, revela o mundo, e, em especial, o Homem, aos outros homens, para que estes tomem, em face ao objeto assim revelado, a sua inteira responsabilidade. Não basta ao escritor ter escrito certas coisas, é preciso ter escolhido escrevê-las de um modo determinado, expondo seu mundo, com elementos estéticos, de criação literária.

O homem que escreve tem a consciência de revelar as coisas, os acontecimentos; de constituir o meio através do qual os fatos se manifestam e adquirem significado. Mesmo sabendo que, como escritor, pode detectar a realidade, não pode produzi-la; sem a sua presença, a realidade continuará existindo. Ao escrever, o escritor transfere para a obra certa realidade, tornando-se essencial a ela, que não existiria sem seu ato criador.

No ato de escrever, o escritor deve solicitar um pacto com o leitor: para que ele colabore em transformar o mundo, a sua realidade. $\mathrm{O}$ escritor dirige à liberdade de seus leitores, visto que a literatura é a tentativa do homem-escritor de criar uma realidade que possa ser exibida no mundo real e modificar as estruturas da sociedade humana. Assim, segundo Sartre, “escrever é, pois, ao mesmo tempo desvendar o mundo e propô-lo como uma tarefa à generosidade do leitor” (Sartre, 1999, p. 49).

Não faz sentido algum separar a repercussão da obra da sua produção porque ela só estará acabada no momento em que repercute e atua, já que, sociologicamente, a arte “é um sistema simbólico de comunicação inter-humana” (Candido, 1980, p. 21). Todo processo de comunicação pressupõe um comunicante (o artista); um comunicado (a obra) e um comunicando (o público). Graças a esse complexo e, principalmente, ao receptor de arte, é que se define o quarto elemento do processo, que é o efeito. 
Em “Leitura: Entre a Crítica e a Criação”, Mello expõe-nos que há um apelo ao receptor em todas as artes, para que este se identifique com aquele que se identificou com o objeto que está sendo representado. Citando Proust, a autora enfatiza que em todo artista há dois seres distintos, o criador e o homem da vida cotidiana, e só se atinge a essência da obra, lendo-a com inteligência e sensibilidade, ou seja, recriando-a pelo ato de leitura.

É o que Sartre quer dizer ao defender a leitura como sinônimo de atividade criadora, insistindo na idéia de que, sem leitura, não há literatura. Em outras palavras,

O ato criador é apenas um momento incompleto e abstrato da produção de uma obra; se o autor existisse sozinho, ele poderia escrever tanto quanto quisesse, jamais a obra como objeto veria a luz [...] a operação de escrever implica a de ler como o seu correlato dialético (Sartre, 1999, p. 50).

Como podemos observar, nas tentativas de definição da Literatura, de modo geral, os estudiosos fazem afirmações sobre a questão da comunicação do texto com o leitor, em obras que não acreditam em um sentido único, comum e permanente. Desse modo, não falamos apenas da criação, mas também da recepção literária. Refletimos sobre um conhecimento geral da literatura, uma compreensão do objeto literário na sua essência, que deve preceder a obra que o escritor pretende criar. Assim, o ato de escrever supõe um descobrimento prévio da literatura, baseado no ato de ler, cujas perspectivas e representações que definem tal ato são modificadas/atualizadas pelo contexto histórico, cultural e social.

\section{Virginia Woolf: consciência artística e posicionamento político}

Investigar até que ponto a produção literária é efetivamente determinada pelo ambiente social ou dele dependente constitui um aspecto comum a três aspectos da relação entre literatura e sociedade: sociologia do escritor, conteúdo social das obras em si e influência da literatura na sociedade. "Em que medida a literatura deve ater-se à vida circundante e, a seu modo, refleti-la e procurar transformá-la?” é uma das perguntas-chave do ensaio de Jean-Paul Sartre, que nos permite refletir sobre o papel de Virginia Woolf enquanto escritora perante a sociedade britânica no início do século XX.

Virginia Woolf (1882-1941) era uma mulher que estava à frente de seu tempo. Pertenceu a uma família da elite intelectual britânica e teve uma educação fundamentalmente vitoriana, em uma época na qual somente os homens tinham direito a frequentar escolas e universidades e a participar diretamente nos assuntos políticos, econômicos e sociais em sua sociedade. Por isso, a educação e formação de Virginia foram obtidas praticamente em casa.

Na casa de seus pais, Leslie Stephen e Julia Duckworth, havia inúmeras reuniões com intelectuais e, a partir dessas reuniões, Virginia desenvolveu sua percepção e visão de mundo. A escritora sabia do domínio masculino em todos os setores da sociedade 
onde ela estava inserida. Sendo contrária às inúmeras injustiças vivenciadas pelas mulheres de sua época, Virginia, principalmente em seus ensaios críticos, protestava contra a exclusão de seu sexo dos papéis políticos e sociais, contra a posição histórica submissa da mulher no lar (podendo ser mãe e dona de casa apenas) e criticava severamente uma sociedade totalmente patriarcal em que não havia direitos iguais para ambos os sexos.

Se voltarmos à noção de que a Literatura nasce de uma concepção ideológica do mundo, podemos pensar na relação entre os seres humanos dentro de uma estrutura social como política. Todo e qualquer escritor é um membro da sociedade e, por isso, pode ser estudado como um ser social. Ele também se posiciona sobre questões de importância social e política; toma parte dos assuntos de seu tempo. Sua ideologia social pode ser expressa em afirmações e atividades extraliterárias.

A relação do escritor com os demais seres humanos está igualmente assentada em ideologias (valores, classes e funções sociais) e essa relação é estabelecida dentro de um conjunto de normas, condutas, regras e estruturas sociais. A Literatura proporciona ao escritor a oportunidade de ter experiências e estas são reveladas ao leitor, por meio da escrita. Nos textos literários, encontram-se formas imaginárias que permitem ao homem experimentar o mundo real.

Apesar das aparências (e de sua origem socioeconômica), Virginia Woolf não se afastou de questões políticas, econômicas e sociais do seu cotidiano. Suas preocupações político-sociais são nítidas e estão espalhadas ao longo de toda sua produção escrita: cartas, diários, ensaios, críticas literárias e romances. Como exemplo, no livro A Casa de Carlyle e outros esboços (2004), David Bradshaw reúne sete pequenos textos escritos por Virginia Woolf do seu diário ao longo de 1909. Por meio desses relatos, que brotaram da própria experiência da escritora, podemos ter acesso aos seus pensamentos sobre a sociedade na qual circulava, focalizando interesses como o patriarcado, o feminismo e o casamento; pois, nesse ano, Virginia tinha 27 anos, solteira, sem filhos e ainda não havia conseguido publicar seu primeiro romance.

Vinda de um ambiente familiar que valorizava a erudição e o desenvolvimento artístico, Virginia Woolf, por volta de 1905, fundava ao lado de sua irmã Vanessa Bell, seu irmão Thoby e de seu futuro marido Leonard Woolf, o círculo literário de Bloomsbury, grupo de jovens intelectuais e artistas cuja característica marcante era o anticonformismo e a busca de uma necessidade autêntica de verdade e liberdade intelectual.

De acordo com Monique Nathan, Bloomsbury era o centro da Londres pensante, liberal e cultivada entre as duas guerras. Além disso, "os traços mais característicos da personalidade literária de Virginia Woolf datam da época em que, sentada à parte, ela ouvia os homens mais brilhantes, mais inteligentes da Inglaterra discutirem os mais graves problemas do momento" (Nathan, 1989, p. 8). Com tantas transformações econômicas (Segunda Revolução Industrial), políticas (morte da Rainha Vitória, guerra dos bôeres) e sociais (valores vitorianos de família, casamento e religião em ruínas, 
movimento feminista) ocorridas no final do século XIX e início do século XX, os artistas sentiam a necessidade de se buscar novas formas de expressão e, dessa maneira, observamos a mudança na concepção do romance moderno inglês.

Neste ponto, podemos falar da interação entre escritor e seu engajamento. Devemos entender a noção de engajamento como o engajamento social que o escritor tem como cidadão do mundo, o ser no mundo. É o compromisso em desvendar o mundo e sua relação com ele. Por meio da escrita, o escritor desvenda o mundo e como a palavra é ação, então desvendar implica em mudar. Sartre posiciona-se contra ao distanciamento do artista em relação às questões sociais, defendendo a tese do engajamento do escritor como forma objetiva de interferir na coletividade e, assim, relacionar-se com a História. Segundo Sartre,

[...] o escritor deve engajar-se inteiramente nas suas obras, e não como uma passividade abjeta, colocando em primeiro plano os seus vícios, as suas desventuras e as suas fraquezas, mas sim como uma vontade decidida, como uma escolha, com esse total empenho em viver que constitui cada um de nós [...] (Sartre, 1999, p. 29, grifo do autor).

Sob esta perspectiva, o escritor tem a responsabilidade de escrever. Ele deve estar engajado socialmente nas suas obras, revelando o mundo por meio da escrita e não se afastando de questões da sua vida cotidiana. É exatamente isso que vemos na obra de Virginia Woolf, principalmente, nos seus ensaios, críticas e em seu primeiro romance.

O processo de composição de The Voyage Out foi interrompido várias vezes, devido não apenas aos momentos de instabilidade emocional e internações da autora, como também pelo seu método de compor. De acordo com informações pessoais, organizadas por Quentin Bell na biografia de Virginia Woolf, a escrita iniciou-se por volta de 1907 e terminou com a publicação em março de 1915. Se considerarmos os acontecimentos da vida de Virginia durante a elaboração de Melymbrosia, podemos observar que a escritora britânica

[...] embarcou com alguma imprudência e [...] pouco escrúpulo, em aventuras emocionais de um tipo bastante desesperado, [além de ser importante] lembrar que na maior parte do tempo ela vivia em um mundo seu - e [...] alguns de seus atos menos justificados se relacionavam com as necessidades desse mundo (Bell, 1988, p. 165).

Este percurso demorado e conturbado caracteriza-se, principalmente, pelo método de trabalho da autora, que consiste em anotar, escrever, revisar, reescrever e datilografar. Por conta disso, há o registro de vários pré-textos chamados pela crítica de “rascunhos”. Esses fragmentos textuais marcam os estágios de maturação de idéias e de adequação de estrutura e conteúdo. Um deles é Melymbrosia, terminado em julho de 1912, descoberto e editado pela pesquisadora Louise DeSalvo nos anos 70 e publicado nos Estados Unidos apenas em 1982. Esse texto - quase completo - é considerado o 
"romance-ensaio”, anterior a versão final que viria a ser oficializada, em 1915, como seu primeiro romance, intitulado The Voyage Out.

Analisando o processo de revisão e reescrita woolfiano, observamos a estreita relação entre as constantes alterações de aspectos formais e conteudísticos de seus textos e a sintonia da escritora com as transformações que seu mundo sofria. Por isso, ao aproximarmos Melymbrosia e The Voyage Out, verificamos a presença do posicionamento crítico acerca do comportamento dos indivíduos de sua sociedade e a conscientização dos assuntos mais importantes de seu tempo. Em outras palavras, é relevante analisar como os elementos sócio-culturais foram filtrados através da concepção estética e habilidade artística de Woolf, promovendo a singularidade de Melymbrosia e The Voyage Out.

A especificidade de cada texto é construída mediante a concepção sobre a vida, a natureza humana e as várias facetas da personalidade humana. Essas posições pessoais são fundamentais na apreensão da realidade e na tentativa de compreender sua existência no mundo. Baseando-se em pessoas e fatos reais, constatamos o limite frágil entre ficção e realidade ao investigarmos a influência de sua visão de mundo no processo de composição de seu primeiro romance.

Tanto em Melymbrosia quanto em The Voyage Out, há uma preocupação clara com os problemas sócio-políticos vivenciados pela sociedade britânica na virada de século. O leitor fica impressionado com a quantidade de informação e com os comentários sociais que a jovem Virginia faz sobre os mais variados assuntos. Em ambos os textos, podemos observar seu compromisso social, ao criticar severamente a os papéis sociais femininos, o colonialismo e o imperialismo britânico. Por exemplo, destacamos um trecho de Melymbrosia que mostra a ironia da autora quanto ao domínio britânico sob os povos colonizados:

"I can't stop thinking of England" [...]. Being on this ship seems to make it so much more vivid - "what it really means to be English. One thinks of all we've done, and our navies, and the people in India and Africa, and how we've gone on century after century, sending out boys from little country villages [...]" (Woolf, 2002, p. 59).

Louise DeSalvo confirma que Woolf foi uma escritora totalmente engajada e consciente dos vários assuntos de seu tempo ao mencionar: "She understood that each meeting between men and women is inside shifting and conflicting social and political forces" (DeSalvo, 2002, p. xx), e, por explorar as relações humanas, Woolf acaba destacando a relação desigual e conflituosa entre os sexos como um de seus temas mais recorrentes, como mostra os trechos seguintes:

"[...] no woman has what I may call the political instinct. You have very great virtues, I am the first, I hope, to admit that; but I have never met a woman who even saw what is meant by statesmanship. I am going to make you still more 
angry. I hope that I never shall meet such a woman. Now, Miss Vinrace, are we enemies for life?” (Woolf, 2002, p. 77).

Este trecho foi retirado de um diálogo entre Rachel Vinrace (heroína) e Richard Dalloway (político influente, com quem Rachel teve seu primeiro beijo). Há um misto de atração física, admiração e contestação entre ambos, uma vez que Richard tem uma atitude assumidamente patriarcal em relação às mulheres e, Rachel, por sua vez, não consegue articular seus argumentos para provar que ele estaria equivocado. Tal trecho aponta a exclusão do sexo feminino dos papéis políticos e a restrição quanto ao lugar da mulher na sociedade.

As experiências individuais de Rachel crescem em termos de quantidade e de significação. A jovem protagonista conheceu Terence Hewet, escritor hospedado no hotel na pequena cidade (fictícia) de Santa Rosa. A relação entre ambas as personagens é construída gradualmente, pois há a descoberta de um mundo novo, repleto de oportunidades e de sentimentos, até então, não vivenciados por Rachel, tais como, amor, felicidade e medo. Embora os dois tenham se apaixonado e ficado noivos, as inúmeras diferenças entre homens e mulheres é, mais uma vez, apontada como um dos obstáculos na relação entre os sexos:

"After all” said Rachel, "what's the use of men talking to women? We're so different. We hate and fear each other. If you could strip off my skin now you would see all my nerves gone white with fear of you" (Woolf, 2002, p. 221).

A dificuldade de comunicação entre as pessoas é exemplificada no trecho seguinte, retirado de um diálogo tenso entre Rachel e St John Hirst (amigo de Hewet e intelectual com uma atitude preconceituosa e soberba):

"But what's the use of your reading it if you can't understand it?" said Hirst fixing her with his severe honest eyes. "I should think it quite possible that you have a mind, but it is doubtful if you can think honestly because of your sex you see” (Woolf, 2002, p. 176).

Esse trecho resume e ilustra bem a relação incompatível entre Rachel e Hirst. A formação intelectual de Hirst - bem como sua prepotência e arrogância - cria um abismo entre ele e as pessoas, em especial, as mulheres. A conduta esnobe e o sentimento de superioridade intelectual masculina, representados nas ações e falas de Hirst, confirmam o pensamento ideológico dominante da época histórica vigente.

É importante ressaltar que, em vários momentos da história, tanto pelo relato do narrador como pelos diálogos entre as personagens, a marginalização e inferiorização da mulher perante a sociedade, em termos de busca por uma profissão; de direito à educação formal; de fruição estética e, inclusive, da capacidade de pensar, compreender e discutir qualquer tipo de assunto são abordadas e criticadas por Virginia Woolf. 
Influenciada pelo período de transição política e de transformação social pela qual a sociedade britânica estava passando, a personagem principal de Melymbrosia e The Voyage Out - Rachel Vinrace - ainda pode ser associada à condição feminina do período vitoriano, isto é, um retrato do comportamento esperado pelas mulheres de sua época no final do século XIX: "era educada numa casa de família tradicional, ela crescia entre o jardim, o piano e a mesa de chá” (Nathan, 1989, p. 22).

Entretanto, Woolf tinha a consciência de era preciso matar the angel of the house - a fada devotada ao lar, tímida e casta: libertar a mulher que, por baixo da autoridade conjugal, representava a cena feliz e harmônica de uma família conveniente. Nesta direção, no final da década de 1920, o maior exemplo de pensamento crítico e expressão artística de Virginia é o polêmico ensaio Um teto todo seu.

Na sua fábula sobre Judite, a fictícia irmã de Shakespeare, Woolf radicalizou sua posição quanto à idéia inconcebível de uma mulher tornar-se escritora, no século XIX, mesmo que tivesse talento: “[...] qualquer mulher nascida com grande talento no século 16 teria certamente enlouquecido, ter-se-ia matado com um tiro, ou terminaria seus dias em algum chalé isolado, fora da cidade, meio bruxa, meio feiticeira, temida e ridicularizada” (Woolf, 1985, p. 65).

Woolf discute abertamente sobre a condição social e política da mulher, defendendo a independência financeira e a liberdade intelectual feminina. Ao mesmo tempo, critica a escravidão doméstica, visto que o papel da mulher era definido basicamente nos termos do casamento e da maternidade.

\section{Considerações finais}

Neste trabalho, tentamos expandir algumas reflexões acerca da relação entre literatura e política. Observamos que a indissociação entre crítica, produção literária e posições marxistas após o período stalinista, acabou gerando visões reducionistas e cristalizadas, que perduram até os dias atuais, havendo a necessidade de revisá-las. A aplicação da teoria literária marxista em questões estéticas deve ser vista como um dos possíveis caminhos de abordagem crítico-metodológica.

Devido às vertentes diferenciadas da tradição teórico-política, poderíamos falar em marxismos, ao invés de um marxismo único. Como literatura e política estão inseridas no contexto sócio-cultural, refletimos também, ainda que rapidamente, sobre o papel do escritor perante a sociedade, o conteúdo social das obras em si mesmas e a influência do ambiente social na produção literária.

Resgatando algumas das tentativas de definição da literatura, sua natureza e função, compreendemos que a literatura é um grande complexo que envolve um escritor, cujo ato criador revela o mundo, por meio da escrita, a outros homens, tendo consciência de sua responsabilidade como cidadão no mundo. O produto final, o texto literário, é destinado a um leitor. Aquilo que se considera literatura depende da maneira pela qual as pessoas se relacionam com a escrita e aquilo que se entende como literário 
é historicamente específico e determinado, segundo interesses particulares daqueles que detêm poder acadêmico, político e social. Assim, vimos que a literatura nasce de uma concepção ideológica do mundo.

Virginia Woolf é um exemplo de consciência literária e posicionamento político. Apesar de sua origem social, a escritora britânica foi uma mulher completamente atualizada e engajada nos assuntos políticos mais importantes de sua época. Os inúmeros interesses woolfianos podem ser identificados em toda a sua obra, em particular, no seu diário de 1909, nos seus ensaios e no processo de composição de seu primeiro romance quando se observa, por exemplo, ataques ao domínio masculino na sociedade britânica, críticas à exclusão do sexo feminino dos papéis políticos e comentários irônicos frente ao imperialismo britânico.

A partir da constatação de mudanças formais e conteudísticas entre Melymbrosia (romance-ensaio, 1912) e The Voyage Out (versão final oficializada, 1915), verifica-se a forte tendência de Woolf em modificar/alterar seu texto em função dos acontecimentos históricos durante o período de escrita do romance. Observa-se também a forma distinta com que a autora construiu suas personagens - coerentes com a realidade social de sua época - em relação com os outros elementos constitutivos da narrativa e, assim, identificam-se os comportamentos, valores e pensamento ideológico da sociedade britânica no início do século XX. Por isso, entende-se que o processo de composição de The Voyage Out, é, de fato, um movimento de "re-visão", de "re-criação", pois a presença do olhar crítico de Virginia e a sua percepção da realidade reavaliam o contexto sócio-histórico britânico.

Por fim, a relação entre literatura, política e sociedade é vista normalmente em termos mais estreitos e extrínsecos. No entanto, tentamos demonstrar (a partir de conceitos de teoria/crítica e seus desdobramentos) que a literatura é capaz de absorver questões referentes ao cotidiano e, em contrapartida, promover questionamentos acerca das implicações sociais e dos significados latentes contidos nas obras literárias, bem como nos ajuda a compreender as interações entre os seres humanos.

\section{Referências bibliográficas}

BELL, Q. Virginia Woolf: uma biografia. Trad. Lya Luft. Rio de Janeiro: Guanabara, 1988.

BRADSHAW, D. “Introdução”. In: WOOLF, V. A Casa de Carlyle e outros esboços. Trad. Carlos Tadeu Galvão. Rio de Janeiro: Nova Fronteira, 2004, p. 17-34.

CANDIDO, A. Literatura e sociedade. 6. ed. São Paulo: Editora Nacional, 1980.

COHEN, W. “Marxist Criticism”. In: GREENBLATT, S.; GUNN, G. (ed.). Redrawing the Boundaries: the transformation of English and American literary studies. New York: The Modern Language Association of America, 1992, p. 320-348. 
DESALVO, L. "A Wound in My Heart”. In: WOOLF, V. Melymbrosia. San Francisco: Cleis Press, 2002, p. ix-xxvii.

EAGLETON, T. Marxismo e crítica literária. Trad. Antônio Sousa Ribeiro. Porto: Afrontamento, 1978.

Teoria da literatura. Trad. Waltensir Dutra. São Paulo: Martins Fontes, 1983, p. 1-17, 209-232.

HATTNHER, A. L. Marxismo, literatura e a poética de Wole Soynka. Fragmentos. Universidade Federal de Santa Catarina, v. 8, n. 1, Florianópolis: Editora da UFSC, p. 7-22, jul-dez 1998.

MELLO, M. E. C. Leitura: Entre a Crítica e a Criação. Disponível em: $<$ http://www.leiabrasil.org.br/doc/doc_suporte/doc_simposio/critica_criacao.doc>.

Acesso em: 7 out. 2009.

NATHAN, M. Virginia Woolf. Trad. Léo Schlafman. Rio de Janeiro: José Olympio, 1989.

NETTO, J. P. O que é marxismo. 9. ed. São Paulo: Brasiliense, 1994.

SARTRE, J. P. Que é a literatura? Trad. Carlos Felipe Moisés. 3. ed. São Paulo: Ática, 1999.

WANDERLEY, J. Literatura. In: JOBIM, J. L. (Org.). Palavras da crítica. Rio de Janeiro: Imago, 1992, p. 253-265.

WELLEK, R. \& WARREN, A. Teoria da Literatura. Trad. José Palla e Carmo. 2. ed. Lisboa: Europa-América, 1955, p. 25-34, 35-46, 117-137.

WOOLF, V. Melymbrosia. San Francisco: Cleis Press, 2002.

The Voyage Out. Oxford: Oxford University Press, 2001.

Um teto todo seu. Trad. Vera Ribeiro. Rio de Janeiro: Nova Fronteira, 1985. 